\title{
Paul Karl Feyerabend. En Defensa de la Continuidad de su Pensamiento ${ }^{1}$
}

Teresa Gargiulo ${ }^{2}$

\begin{abstract}
RESUMEN: Entre los estudios críticos que existen en torno a la obra de Paul Feyerabend predominan aquellos que subrayan una discontinuidad radical entre la versión temprana y tardía de su pensamiento. Todo ello contribuye a que dispongamos de una visión fragmentada e incompleta de un pensador que evoluciono hasta el 1994, año de su fallecimiento. Nuestro propósito es ofrecer una explicación de su itinerario intelectual de tal modo que quedé patente su continuidad en la clave de sus críticas contra los falsos absolutos erigidos por el positivismo lógico y el racionalismo científico. Mostraremos las diversas cuestiones que Feyerabend aborda en las distintas épocas de su vida pero, al mismo tiempo, subrayaremos la unidad o coherencia lógica que existe en su revisión crítica de la racionalidad científica. Nos preocuparemos por entender las razones por las cuales nuestro filósofo de la ciencia va trasladando sus distintos focos de discusión o crítica.
\end{abstract}

PALABRAS CLAVE: Feyerabend. Inconmensurabilidad. Absoluto. Positivismo Lógico. Racionalismo.

\section{INTRODUCCIÓN}

Entre los primeros especialistas y autoridades sobre nuestro epistemólogo debemos nombrar a John Preston (1997a) quién tiene el mérito de ser el primero en publicar un estudio sistemático sobre la obra de nuestro pensador junto con su correspondiente biografía, titulada Feyerabend, Philosophy, Science and Society. No obstante, cabe destacar que dicho trabajo defrauda la intención de presentar una visión completa del pensador en cuestión. Según Preston (1997a, p. 7-8) en Feyerabend habría una discontinuidad radical entre la versión temprana y tardía de su pensamiento. La segunda etapa, según él, comenzaría en 1970 con su ensayo Contra el método, la cual estaría marcada por el abandono del modelo de adquisición de conocimiento desarrollado anteriormente. Pero Preston no da razones que justifiquen este giro que

\footnotetext{
${ }^{1}$ Agradezco a los réferis anónimos las observaciones formuladas a la primera versión de este trabajo.

${ }^{2}$ Doctora en Filosofía por la UNCuyo, Argentina. Es becaria posdoctoral de Conicet (Consejo Nacional de Investigaciones Científicas y Técnicas) y miembro del Instituto de Filosofía de la UNCuyo. Prof. Titular de Epistemología en la Universidad de Congreso. Sus áreas de interés son la Epistemología y la Filosofía de las Ciencias y sus últimas publicaciones se centran en el pensamiento de Paul Feyerabend. E-mail: gargiulomteresa@gmail.com
} 
aparentemente caracterizaría la obra del vienés. A lo largo de ocho capítulos, se limita a analizar y discutir los temas y obras que produjo nuestro epistemólogo entre la década del 50 y del 60. Sólo dedica los dos últimos capítulos a abordar de un modo general la segunda gran fase de su filosofía y solo con ánimo de exponer las bases de su filosofía política y de explicar porqué el relativismo, que atrajo tanto a la audiencia del último Feyerabend, es visto por muchos filósofos como insostenible.

En el año 1999 la Australasian Association for the History, Philosophy and Social Studies of Science organizó una revisión del libro de Preston. Aquí especialistas como George Couvalis, Gonzalo Munévar, Eric Oberheim, y Hoyningen-Huenen ponen de manifiesto las erróneas interpretaciones de Preston, así como el carácter incompleto de sus investigaciones (cf. COUVALIS, 1999, p. 206; MUNÉVAR, 1999, p. 216; OBERHEIM; HOYNINGENHUENE, 1999, p. 226). No obstante, ninguna de estas recensiones críticas se ocupa de sus últimas obras, y menos aún ofrece una visión de conjunto que permita comprender los verdaderos problemas que intenta resolver nuestro epistemólogo.

El hecho que exista abundante bibliografía en torno a la obra temprana de Feyerabend, es decir, la correspondiente a las décadas del '50 y '60 se debe a que durante estos ańos participa activamente en journals, encuentros y jornadas con tesis de tal audacia que lo convirtieron en uno de los filósofos de la ciencia más importantes y en un referente con el cual discutieron los más importantes epistemólogos de la época ${ }^{3}$. Sin embargo, luego de la edición del '75 de Against Method, muchos colegas se sintieron obligados a refutarlo o, incluso, a denostarlo. En cierto sentido, se lo excluyó de los ambientes académicos, revistas y editoriales específicos de la filosofía de la ciencia, en los que se había movido hasta entonces. Esto tuvo como directa consecuencia el hecho de que se desconozca, en general, la posterior evolución de su pensamiento y su extensa producción intelectual.

\footnotetext{
${ }^{3}$ Feyerabend tuvo una relación cercana con Popper en 1950, con Kuhn a principios del 1960 y con Lakatos en la década del ' 60 y del '70. Esto le permitió participar activamente en las discusiones que tenían lugar entre aquellos destacados epistemólogos. La obra de Feyerabend puede ser entendida cómo la respuesta a las dificultades que se plantean en la Filosofía de la Ciencia en la segunda mitad del siglo XX. De aquí que nuestra investigación no solo significa un avance en la comprensión de la obra de Feyerabend sino que, por lo mismo, ayuda a iluminar -al menos desde la óptica feyerabendiana - una cuestión que atraviesa toda la filosofía de la ciencia, a saber, la relación entre ciencia y metafísica.
} 
A pesar de la cuantiosa bibliografía que es posible encontrar sobre Feyerabend, se advierte que la gran mayoría de ella aborda aspectos restringidos y particulares de su obra: existen estudios que presentan su pensamiento como una prolongación de las tesis de Popper (cf. PRESTON, 1997a, p. 9 y ss.; BRONNCANO, 1999, p. 9-34; WATKINS, 2000, p. 48; OBERHEIM, 2006, p. 77-115; FARRELL, 2000; 2003, p. 151 y ss), de Wittgenstein (PRESTON, 1997a, pp. 23 y ss) o de Mach (HENTSCHEL, 1985; ZAHAR 1981); u otros que lo exponen en continuidad con la filosofía neo-kantiana (BoYD, 1992; OBERHEIM, HOYNINGUEN-HUENE, 1997), hegeliana (KLIMOVSKY, 2001), escéptica (KADVANY, 1996; MAIA NETO, 1991; MUSGRAVE, 1978; HOOKER, 1991) o con el constructivismo social (GELLNER, 1975; CULP, 1995; KITCHER, 1992; SHAPIN, 1975). Pero dichas aproximaciones adolecen de no haber comprendido el pensamiento de Feyerabend como una totalidad.

Es necesario destacar otros trabajos posteriores como el de Farrell (2003) y Eric Oberheim (2006), quienes esbozan una visión global de su itinerario filosófico. Ambos dan una caracterización completa de su obra en cuanto que abarcan las tesis que nuestro pensador desarrolló hasta sus últimos años.

Farrell aborda la noción de racionalidad en la filosofía tardía del vienés. Muestra cómo nuestro pensador se opone a considerar la racionalidad como un conjunto de reglas universales, necesarias y objetivas; y en su lugar propone una racionalidad contextual, inherentemente histórica y flexible. Al explicar la intención de Feyerabend de romper con la tradicional distinción entre razón práctica y razón teórica, y exponer su filosofía en términos de realismo y relativismo, Farrell ofrece una de las llaves necesarias para poder entender la epistemología y la metafísica de Feyerabend.

Oberheim, por su parte, en Feyerabend's Philosophy (2006) expone el pensamiento del Feyerabend desde los originales lo cual permite conocer algunas de las variaciones y correcciones que fue introduciendo en las distintas ediciones o publicaciones de una misma obra. Su libro, además, tiene el mérito de ofrecer un claro panorama de los pensadores que paulatinamente fueron influyendo en su obra.

Tanto Farrell como Oberheim han procurado demostrar contra Preston la continuidad y coherencia que existe en la obra de Feyerabend. Farrell (2003, p.129) demuestra que se puede proyectar una trayectoria constante en la filosofía de Feyerabend en los términos de la proliferación teórica. Según él, la 
proliferación teórica permitiría dar cuenta de su lucha contra todo elemento dogmático en la ciencia, de su relativismo y de su crítica al positivismo lógico y el racionalismo crítico. Eric Oberheim, en cambio, asegura que la clave que atraviesa todo el pensamiento del vienés es su lucha contra todo tipo de conservadurismo o dogmatismo con su concomitante invitación a proponer teorías inconmensurables:

Pero una mirada más atenta a los primeros trabajos de Feyerabend muestra el retorno, asombrosamente consistente, de cierta constante intelectual que se compone de dos elementos: los objetos, diversos por lo demás, de su crítica aparecen todos como formas también diversas del conservadurismo conceptual, y la crítica que de ellos hace Feyerabend se basa siempre en la suposición de que existen alternativas inconmensurables, hasta ahora no consideradas, a las ideas dominantes. (OBERHEIM; HEIT, 2013, p. 19).

El propósito del presente estudio es ofrecer -en continuidad con los estudios de Farrell y Oberheim- una explicación del itinerario intelectual de Feyerabend tal modo que quede patente la continuidad de su pensamiento. Aunque tal exposición no se hará en la clave de su proliferación teórica o de su lucha contra el conservadurismo conceptual, pues de esto ya han dado cuenta tanto Oberheim como Farrell. Se demostrará la unidad de su obra analizando su crítica contra los falsos absolutos erigidos por el positivismo lógico y el racionalismo científico.

Expondremos el camino por el cual va superando y refutando paulatinamente las contradicciones e inconsistencias que encuentra en su formación positivista, en el racionalismo crítico y en el relativismo que sostuvo entre las décadas del 70 y 80. Para ello argumentaremos cómo su teoría pragmática de la observación (1), su doctrina de la inconmensurabilidad (2) y su anarquismo epistemológico (3) constituyen reducciones al absurdo de los intentos del positivismo y del racionalismo por fundamentar la ciencia. Finalmente mostramos como esta crítica lo conduce, al final de su vida, a redescubrir la necesidad de formular una explicación de la racionalidad científica que no repita las inconsistencias que fueron el objeto de sus críticas (4).

\section{Critica al modelo NeO-Positivista del Significado}

En los años 50 Feyerabend adopta las tesis características de la naciente Filosofía de la Ciencia en sus dos vertientes: el positivismo lógico del Círculo 
de Viena a través de su participación en los debates surgidos en torno a Círculo de Victor Kraft, y el deductivismo popperiano en sus estudios posdoctorales en la London School of Economics.

Feyerabend $(1994 / 1995 \text {, p. } 67)^{4}$ en su autobiografía reconoce haber adoptado, ente los ańos 1940 y principios de 1950, tesis características del positivismo lógico. Refiriéndose a este período intelectual se define a sí mismo como un empirista incondicional. Es efectivamente un empirismo antimetafísico lo que lo conduce pensar en aquellos años que la ciencia es la base del conocimiento y a definir la ciencia como empírica. Sostiene que "[...] las empresas no empíricas o son lógicas o carecen de sentido" (1994/1995, p. 69). Con firmeza insiste en la necesidad de eludir toda intervención de la metafísica en el campo de la ciencia. En su autobiografía, escribe: "[...] yo me basaba en los datos sensoriales y la lógica (o lo que creía que era la lógica), [...y] replicaba diciendo que, por desgracia, los científicos no se habían liberado todavía de sus cascarones metafísicos" (FEYERABEND, 1994/1995, p. 72).

No obstante, en cuanto Feyerabend estudia las Investigaciones Filosóficas de Wittgenstein y los problemas en torno a la interpretación de la teoría cuántica comienza una revisión crítica de su propia formación positivista. Esto da razón de ser a la fuerte crítica que dirige contra el modelo positivista del significado tanto en su tesis doctoral ${ }^{5}$ como en los artículos que publica entre los años 55 y 69.

A través de su participación en los debates surgidos en torno a Victor Kraft y de sus investigaciones en la London School of Economics bajo la supervisión de Popper, Feyerabend toma contacto con algunas de las críticas al positivismo lógico. Desde el 1949 hasta 1953 Feyerabend es uno de los estudiantes líderes del Círculo de Kraft, el cual es definido por él mismo como "[...] una versión estudiantil del antiguo Círculo de Viena” (FEYERABEND, 1994/1995, p. 74). Kraft no sólo dirige este círculo, sino que también supervisa sus estudios doctorales. Feyerabend asegura que gran parte de su tesis doctoral como muchos

\footnotetext{
${ }^{4}$ Para facilitar la lectura, las citas de las obras de Paul Feyerabend tendrán doble fecha. La primera se refiere al año de la primera publicación y la segunda a la publicación consultada. El objetivo de la doble fecha es dar cuenta de un orden cronológico de las publicaciones y, al mismo tiempo, remitir al lector a los lugares precisos donde pueda cotejar las citas textuales, las paráfrasis y las referencias generales.

${ }^{5}$ En 1951, en la disertación de su tesis doctoral, emplea la noción de inconmensurabilidad -aunque no el término mismo- para rechazar el rol que el empirismo lógico concede a las oraciones observacionales en la comprobación de teorías. Cf. Zur Theorie der Basissätze (Disertación del PhD) - Universitäts Bibliothek Wien, 1951, 149 p. Se puede encontrar una versión más abreviada en FEYERABEND, 1958/1981a.
} 
de sus primeros artículos son el resultado directo de los debates surgidos entre los miembros del Círculo y de las visitas ocasionales de Hollitscher, Felix Ehrenhaft, von Wright, Elizabeth Anscombe y Wittgenstein a aquellas reuniones. Aún más, Feyerabend (1994/1995, p. 74) reconoce explícitamente que Kraft "había anticipado algunas ideas que después se asociaron con Popper”. En la recensión que escribe a la Epistemología de Kraft asegura que éste había señalado la irracionalidad del empirismo lógico al pretender liberar la ciencia de sus ingredientes metafísicos (Feyerabend, 1963, p. 319). Kraft demuestra -tal como señala John Preston (1997a, p. 18) - que el método inductivo es incapaz de garantizar por sí mismo los enunciados observacionales. Estas demostraciones de Kraft facilitaron el posterior acercamiento de Feyerabend a la filosofía de Popper y ofrecieron abundante materia para sus ataques contra los distintos criterios positivistas del significado.

Los intentos del positivismo lógico por definir la ciencia desde una perspectiva lógica-lingüística constituyen el fundamento de las distintas variantes de lo que Feyerabend designa como la concepción semántica de la observación. Esta concepción semántica abarca para Feyerabend (1958, p. 30, n. 20) tanto al instrumentalismo como al reduccionismo semántico de Carnap. El instrumentalismo interpreta la teoría científica como una herramienta de predicción y, en cuanto tal, sus enunciados teóricos carecen de significado descriptivo. Su función se limita a predecir el comportamiento de un fenómeno en lenguaje observacional. El reduccionismo, en cambio, dicta que las hipótesis teóricas poseen significado en la medida que pueden ser reducidas a un lenguaje observacional.

La crítica que Feyerabend dirige contra el modelo positivista del significado consiste en mostrar que el significado de las oraciones observacionales es determinado por la ontología de las teorías en virtud de la cual se explica la naturaleza de lo que se observa. Invierte el modelo positivista del significado; pues mientras el positivismo lógico asegura que las proposiciones metafísicas no son ni verdaderas ni falsas, simplemente, carecen de sentido, Feyerabend postula que el sentido de las proposiciones depende de los elementos metafísicos que atraviesan la teoría. En su autobiografía escribe:

Los positivistas eran partidarios de una "filtración ascendente" del significado, como Meehl la llamaba: los enunciados de la observación (los situábamos en la parte inferior de nuestros diagramas) son significativos, mientras que los enunciados teóricos tomados por sí mismos no lo son, sino que reciben el significado a través de vínculos lógicos que los unen a los enunciados de la observación. Continuando la tendencia inaugurada en mi artículo de 1958, 
yo sostenía que los significados se mueven en la dirección contraria. Los datos sensoriales, en y por sí mismos, carecen de significado: sólo son. Si a una persona se le dan datos sensoriales y nada más estará completamente desorientada. El significado proviene de las ideas. El significado, por tanto se "filtra en sentido descendente", desde el nivel teórico hasta el nivel de la observación. (FEYERABEND 1994/1995, p. 113).

La interpretación de los términos científicos no emerge de la cerrada atención a los 'hechos' pues - tal como se ha visto - pueden ser objetos de múltiples e incluso divergentes interpretaciones. Esto conduce al filósofo vienés (1960/1981a, p. 42) a reconocer que la interpretación de los términos científicos no depende de su conexión con la experiencia, a través de sentencias observacionales, sino de los elementos metafísicos contenidos en la teoría. Necesitamos - afirma Feyerabend (1958/1981a, p. 36) - “[...] una fuente no-observacional para las interpretaciones. Tal fuente es provista por

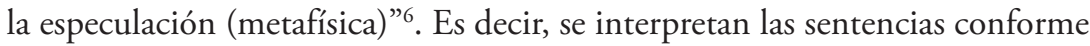
a la ontología que informa la teoría elegida. A cada lenguaje se le aplican las connotaciones ontológicas propias del todo teórico.

Feyerabend (1960/1999, p. 48; 1962/1989, p. 149) cuestiona la base o el núcleo estable e intersubjetivo que - según el neo-positivismo garantiza el carácter objetivo y científico de una teoría. De este modo, sus ataques se extienden no sólo a los criterios positivistas del significado, o al modelo positivista de comprobación teórica, sino que en definitiva alcanzan los distintos intentos del positivismo lógico por definir la ciencia en una oposición dialéctica con la metafísica.

Feyerabend nunca quiso elaborar en cuanto tal una teoría del significado. De aquí que se discuta entre los especialistas si Feyerabend estuvo interesado en desarrollar una teoría del significado. Richard Rorty (1975) y Ian Hacking (1980) aseguran que el vienés no sólo no necesita formular ninguna teoría del significado sino que desprecia tales cuestiones. Numerosos pasajes de la obra del vienés parecen apoyar esta opinión en cuanto que exponen los argumentos de Feyerabend en contra de la filosofía analítica o lingüística (cf. FEYERABEND, 1955 , p. $480-483$; 1956 , p. 96 n. 4; 1960, p. 247; 1960/1981b, p. 219-220; $1961 / 1995$, p. 385; 1961/1999, p. 75; 1963, p. 320; 1964, p. 250 y ss; 1965, p. 226 n. 10 y ss.; 1966b, p. 9; 1975/1999, 197-198).

6 "It follows that we need a non-observational source for interpretations. Such a source is provided by (metaphysical) speculation [...]". (TN) 
Pero, a pesar de los ataques a lo que él reconocía como la 'filosofía de Oxford', o precisamente a ocasión de sus críticas contra la teoría pragmática y la teoría fenomenológica del significado, desarrolló su propia teoría del significado. De aquí que exista una abundante bibliografía que adjudique a Feyerabend una teoría pragmática del significado (ACHINSTEIN 1964; PRESTON 1997a, p. 23-39; PUTNAM 1965; SHAPERE 1966; OBERHEIM 2006, p. 43-70; GENTILE 2007, p. 114-115).

Preston (1999, p. 235), por su parte, no puede entender el abandono radical de Feyerabend de las cuestiones referentes al análisis lógico del lenguaje que lo ocupan durante gran parte de sus publicaciones de los años $60 \mathrm{y}$ principios de los 70 .

La razón del posterior abandono de los análisis lingüísticos que parece no advertir Preston estriba en que a Feyerabend no le interesa, ni siquiera en sus artículos tempranos, terciar o participar en el proyecto de erigir una teoría positivista del lenguaje, ni en oponer a ella una nueva teoría del lenguaje. Su intencionalidad en estos años se concentra en denunciar el falso fundamento sobre el cual se erige un modelo axiomático de ciencia y para demostrarlo, a modo de una consecuencia accidental, formula una teoría pragmática del significado. El sentido de esta teoría lingüística no es sino reducir al absurdo el proyecto positivista del significado (cf. FEYERABEND, 1981, p. xv-xvi).

Feyerabend expresa su crítica en los mismos términos con los que se plantea y desarrolla este modelo formal de ciencia, es decir, desde los enfoques lógicos y lingüísticos que predominaban la filosofía analítica. Pero una vez que con su teoría pragmática de la observación y su doctrina de la inconmensurabilidad demuestra la imposibilidad de reducir lógicamente los términos de una teoría a la otra, y el contrasentido del principio de autonomía de los hechos $-\mathrm{y}$, por tanto, objeta la explicación del progreso científico y el modelo de comprobación teórica del positivismo lógico- la utilización de tales recursos carece de sentido. De aquí que a su preocupación inicial por los asuntos del significado la califico posteriormente como inútil para una teoría del conocimiento y de la ciencia (Cf. FEYERABEND, 1955, p. 480-483; 1956, p. 96 n. 4; 1960, p. 247; 1961/1995, p. 385; 1963, p. 320; 1960/1981b, p. 219-220; 1961/1999, p. 75; 1964, p. 250 y ss; 1965, p. 226 n. 10 y ss.; 1966b, p. 9; 1975/1999, p. 197-198).

Pero no solo su teoría pragmática de la observación constituyó en sí misma una reducción al absurdo de intento positivista de fundamentar 
la ciencia en enunciados observacionales. También su doctrina de la inconmensurabilidad debe ser leída en esta clave hermenéutica. En la próxima sección, expondremos la inconmensurabilidad en tanto ella significa una objeción a un modo particular de entender y dar cuenta del progreso científico.

\section{Su DOCTRINA DE LA INCONMENSURABILIDAD}

En Explicación, Reducción y Empirismo (1962) Feyerabend opone su doctrina de la inconmensurabilidad a la teoría de la reducción de Nagel (1961/1981) y la teoría de la explicación de Hempel y Oppenheim (1948) y por tanto a un modo particular de concebir la teoría y la actividad científica.

Éstos conciben la teoría científica cómo un cuerpo de enunciados, cuyos principios generales son lógicamente deducibles de la información contenida en los términos descriptivos u observacionales (FEYERABEND, 1962/1989, p. 49). Una teoría será verdadera o verosímil en cuanto es validada por la experiencia. Habrá progreso científico en la medida que la nueva teoría aumente el contenido empírico de las teorías precedentes. Reducir o explicar una teoría exige demostrar cómo la nueva teoría es más fecunda y al mismo tiempo abarcativa de todo cuanto hay de verdadera y bueno en las teorías más antiguas. Las viejas teorías no son más que una derivación de las nuevas, en un sentido lógico estricto. De aquí que el significado de los términos observacionales de las viejas teorías permanezca intacto e invariable al ser abarcados o reducidos a la nueva teoría.

Feyerabend, en primer lugar, impugna uno de los pilares fundamentales del positivismo lógico, a saber, la tesis de una evidencia observacional objetiva, neutra e independiente de toda teoría. La evidencia, señala el epistemólogo, no consta sólo de hechos puros y simples, sino, y sobre todo, de hechos analizados, modelados y construidos de acuerdo con alguna teoría (FEYERABEND, 1962/1989, p. 76). Este carácter construido de la evidencia es puesto de manifiesto por el hecho de que "uno y el mismo conjunto de datos observacionales es compatible con teorías muy distintas y mutuamente inconsistentes" (FEYERABEND, 1962/1989, p. 73). Esto se debe a que las teorías están informadas y organizadas por una ontología distinta en virtud de la cual ofrecen explicaciones o descripciones incompatibles o, más propiamente, inconmensurables de los mismos hechos observacionales. 
En segundo lugar, y como consecuencia de lo primero, refuta la tesis de la estabilidad del significado. Cuando se pasa de una teoría A a una teoría $\mathrm{B}$, afirma el filósofo vienés, es algo mucho más radical que la incorporación de A, sin modificación alguna, al contexto de B. Mas bien, lo que tiene lugar es una sustitución de la ontología de A por la ontología de B, lo cual redefine no solo los términos teóricos y observacionales, sino que en general rehace toda la evidencia de A (FEYERABEND, 1962/1989, p. 77). Luego es imposible que una teoría sea reducida o explicada en los términos de la nueva teoría; y que los significados de aquella permanezcan invariables ${ }^{7}$.

De este modo, Feyerabend cuestiona el intento del positivismo lógico de fundamentar la ciencia y el progreso científico en la lógica y la observación empírica. No es la mera consistencia con los hechos lo que prueba la validez de una teoría. Tampoco es la lógica el único juez que dirime la cuestión del desarrollo científico. Existen otros factores que rigen semejante desarrollo, entre los cuales se destacan los elementos metafísicos.

Ahora bien, Feyerabend (1962/1989, p. 103) también advierte el peligro de que estos supuestos metafísicos se constituyan en dogmas. Toda teoría crea sus propios métodos de observación y medición; codifica los modos en los que deben interpretarse los resultados; establece una terminología unificada en conformidad con la ontología que la anima mientras que rechaza todos aquellos resultados que no puedan acomodarse a ella. Se disponen todos los elementos de tal modo que su punto de vista queda reforzado. Así una teoría científica se constituye en una verdad absoluta con un pobre contenido empírico que modela a su antojo. Se torna un círculo vicioso, herméticamente cerrado, donde la realidad no puede mostrar otra cosa que lo que ella quiera hacerle decir (FEYERABEND, 1958/1981a, p. 34; 1962/1989, p. 107-108).

En orden a superar estos dogmatismos Feyerabend propone criticar y examinar cuidadosamente los supuestos metafísicos involucrados y considerar teorías ontológicas alternativas. He aquí su conocido Pluralismo metodológico que consiste, por un lado, en omitir o violar ciertos métodos e introducir hipótesis

\footnotetext{
${ }^{7}$ Para el vienés la irreductibilidad del contenido, la variación en el significado de los términos, las dificultades de traducción recíproca de sus términos, la incapacidad de determinar un referente común, la ausencia de una mutua inteligibilidad y de estándares comunes para evaluar distintas teorías comprensivas, etc. no son más que el resultado de la inconsistencia ontológica entre teorías no instánciales o comprehensivas (cf. FEYERABEND, 1958, p. 78-79 y p. 90-91; 1958/1981a, p. 29 y $35 ; 1961 / 1999$, p. 52-54; 1962/1981a, p. 323; 1962/1989, p. 77-78, 137-138; 1965/1981b, p. 109-110; 1975/1992, p. 102-103). En este sentido, la explicación que ofrece Feyerabend de la tesis de la inconmensurabilidad parece ser más radical y abarcativa que la de Kuhn.
} 
"ad hoc" o teorías alternativas inconsistentes con las teorías imperantes o con los hechos bien establecidos, lo cual permitiría no sólo aumentar el contenido empírico de la ciencia, sino también disponer de un material empírico capaz de poner en dificultad o incluso en crisis las teorías autoconsistentes (cf. FEYERABEND, 1975/1992, p. 7-8 y 16). Por otro lado, su pluralismo exige someter a una verdadera discusión filosófica los supuestos metafísicos implícitos en las teorías científicas, evitando así que se petrifiquen en dogmas. Por ejemplo con respecto al problema de la interpretación de la física cuántica, Feyerabend (1968, p. 309) insiste reiteradamente que no habrá progreso hasta que no exista una verdadera discusión filosófica en torno a sus supuestos metafísicos. No avanzará hasta que sus argumentos dogmáticos sean remplazados por argumentos que se dirijan hacia los problemas filosóficos fundamentales.

Feyerabend (1957, p. 356) explica que desde una concepción positivista muchos físicos ignoran o rechazan explícitamente el carácter especulativo o metafísico del principio de complementariedad y postulan, consecuentemente, su validez absoluta y definitiva. Y cita como ejemplo de ello a Rosenfeld quien asegura que apelar a preconcepciones metafísicas para fundar la validez de este principio físico sería un procedimiento a-científico (Feyerabend 1962/1981a, p. 316.). Frente a ello, el filósofo devela los supuestos metafísicos implícitos en el principio de complementariedad, mostrando así la incoherencia del positivismo postulado por Rosenfeld. En Materialism and the Quantum Theory (1966) escribe:

Las filosofías parasitarias de esta clase no son para nada un fenómeno nuevo. Por lo general éstas son los remanentes de un punto de vista que una vez se mostró eficiente cuya utilidad ha sobrevivido, pero que todavía se adhiere a él dogmáticamente. Los filósofos expertos deberían haber sido capaces de distinguirse entre éstas y las ideas que condujeron a la teoría cuántica en primer lugar. Esto no pasó; confundieron la teoría con sus interpretaciones parásitas y de vez en cuando aquella era aún criticada debido a alguna popularización desinformada de la cual venía a tener noticia el propio autor. Debe darse la bienvenida cuando las ideas son tomadas en serio y cuando sus efectos generales son examinados y criticados con cuidado. Pero es lamentable cuando no permiten a ideas realmente interesantes entrar en discusión y cuando solamente se presta atención a los cambios piadosos. (FEYERABEND, 1966a, p. 416-417) ${ }^{8}$.

8 "Parasitic philosophies of this kind are not at all a new phenomenon. Usually they are the remnants of a once efficient point of view which have outlived their usefulness but are still adhered to dogmatically. Expert philosophers should have been able to distinguish between them and the ideas which led to the quantum theory in the first place. This did not happen; the theory was confounded with its parasitic interpretations and was occasionally criticized even because of some uninformed popularization that had come to the author's notice. It is to be welcomed when ideas are taken seriously and when their general 
Feyerabend (1958/1981a, p. 21; 1966a, p. 416-417) rechaza con insistencia el modo acrítico e ingenuo de los físicos de aceptar una determinada ontología, con la consideración explícita o implícita de que otras alternativas son simplemente contranaturales. En orden a superar estas filosofías Feyerabend se ocupa de criticar y examinar cuidadosamente los supuestos metafísicos del principio físico y de considerar teorías ontológicas alternativas.

A través del problema de la inconmensurabilidad nuestro epistemólogo demuestra que las teorías científicas no son determinadas únicamente por los hechos observacionales sino que la especulación metafísica juega en ellas un rol realmente importante. Bosqueja un modelo de ciencia donde la metafísica no sólo tiene un importante papel pre-científico, como postulaba Popper, sino que el mismo quehacer científico está animado por una constante discusión y reflexión metafísica. Refuta la falsa distinción entre contexto de descubrimiento y contexto de justificación, entre ciencia y metafísica, mostrando que esta última es imprescindible para que la ciencia recupere su auténtico valor descriptivo:

Una de las objeciones que pueden levantarse contra la discusión precedente es que ha confundido dos contextos que están esencialmente separados; un contexto de descubrimiento y un contexto de justificación. El descubrimiento puede ser irracional y no necesita seguir ningún método reconocido. La justificación, por otra parte, o, para usar la Palabra Sagrada de una escuela diferente, la crítica, empieza sólo después de que sean hechos los descubrimientos y procede de una manera ordenada. Ahora bien, si el ejemplo dado aquí y los ejemplos a los que he recurrido en escritos anteriores muestran algo, esto es, simplemente, que dicha distinción apunta a una situación que en la práctica no se presenta jamás Y si presenta lo que refleja no es otra cosa que una paralización temporal del proceso de investigación. Por ello debe ser eliminada tan rápidamente como sea posible.

La investigación es, en su mejor condición, una interacción entre teorías nuevas que se enuncian de una manera explícita y viejas formas de ver las cosas que se han infiltrado en el lenguaje de observación. No es una acción unilateral de las unas sobre las otras. Razonar dentro del contexto de la justificación presupone, sin embargo, que un elemento de este par, la observación, se ha congelado, y que los principios que constituyen los conceptos de observación se petrifiquen a los principios de un punto de vista recientemente inventado. El primero de los dos caracteres indica que la discusión de principios no se ha llevado a cabo tan vigorosamente como

effects are carefully examined and criticized. But it is regrettable when really interesting ideas are not allowed to come to the fore and when attention is paid only to the pious afterthoughts". (TN.). 
sería deseable; el segundo carácter revela que esta falta de vigor puede ser debida a alguna preferencia irrazonable y quizás ni siquiera explícita. ¿Pero es siquiera medianamente razonable dejarse dominar por una preferencia inarticulada de este tipo? ¿Es inteligente hacer de esta preferencia la razón de ser de una distinción que separe dos modos de investigación enteramente diferentes? ¿O no deberíamos más bien pedir que nuestra metodología trate exactamente del mismo modo las afirmaciones explícitas y las implícitas, las teorías dudosas y las intuitivamente evidentes, los principios conocidos y los principios que se tienen inconscientemente, y que provea los medios para el descubrimiento y la crítica de estos últimos? Abandonar la distinción entre un contexto de descubrimiento y un contexto de justificación es el primer paso hacia la satisfacción de esta demanda. (FEYERABEND, 1970/1989, p. 89-90).

La inconmensurabilidad en cuanto descubre lo metafísico en el seno de la actividad científica pone en crisis un modelo de ciencia que es heredero de una tradición epistemológica que intenta definir lo científico a expensas de lo metafísico. La epistemología moderna, y luego la filosofía de la ciencia, en sus intentos de fundar o definir la objetividad o la racionalidad del conocimiento científico ideo todo tipo de distinciones. A saber, la distinción de Hume (2004) entre cuestiones de hecho y relaciones entre ideas ; distinción que fue retomada más tarde por Kant (2003) en su división entre juicios sintéticos y juicios analíticos, y posteriormente por el positivismo lógico para el cual la distinción analítico-sintético se convertirá en la piedra angular de la teoría empirista del significado (cf. HAHN; NEURATH; CARNAP, 2002). A esto se suma la distinción entre teoría y método que caracteriza al racionalismo científico.

Para Feyerabend la inconmensurabilidad implica una crisis de esta tradición epistemológica que busca dar cuenta de la objetividad, la racionalidad y el progreso científico en los términos de dichas distinciones. Ella demuestra que la concepción de ciencia del empirismo lógico y del racionalismo crítico al excluir los elementos metafísicos del cuerpo científico, es incapaz de dar cuenta del progreso, la racionalidad y la objetividad científica en un cierto tipo de transiciones teóricas. Éstos no ofrecen criterios para discernir si las nuevas teorías se refieren al mismo contenido empírico, si implican un progreso respecto a la anterior (cf. Feyerabend, 1970/1981, pp. 152-153), o si es racional su manera de delimitar lo objetivo de lo metafísico (cf. FEYERABEND, $1975 / 1992$, p. 265-266; 1993/2008, p. 207, 242-243; 1988, p. 16). 
Feyerabend argumenta que todos aquellos elementos metafísicos o pre-racionales -que la Concepción Heredada recluía en el contexto de descubrimiento- son medulares en el contexto de justificación quedando así desdibujada la frontera que el positivismo lógico y el racionalismo crítico traza entre la metafísica especulativa y las ciencias naturales. Dentro de esta tradición, la inconmensurabilidad tal como fue pensada por Feyerabend amplia y enriquece las concepciones de ciencia axiomáticas o metodológicas destacando los elementos metafísicos u ontológicos que la componen. La inconmensurabilidad demuestra que la ciencia no está constituida únicamente por elementos lógicos, observacionales y metodológicos; sino que los elementos metafísicos son un componente ineludible del quehacer científico.

La consecuencia lógica del problema de la inconmensurabilidad -tal cual fue pensada por Feyerabend- no es el denuesto de la ciencia. Feyerabend sólo quiere mostrar con ella que es falsa la contradicción entre ciencia y metafísica. Ahora bien, si esta separación es falsa, la inconmensurabilidad, en un sentido negativo, impide retomar dialécticas o supuestos del positivismo lógico y del racionalismo crítico -o de la epistemología moderna en general- , a la hora de fundar la objetividad o la racionalidad científica. En un sentido positivo, la inconmensurabilidad afirma la cientificidad, es decir, la posibilidad de prueba y de discusión racional de los elementos metafísicos. Feyerabend (1965, p. 150-151) accede con su doctrina de la inconmensurabilidad y su Pluralismo teórico a una concepción de la racionalidad científica más amplia, omnicomprensiva y capaz de abordar tesis metafísicas.

Una vez comprendida la intencionalidad que persigue Feyerabend con su doctrina de la inconmensurabilidad se puede captar y entender el tono irónico que tiene su propuesta de un relativismo y un anarquismo epistemológico. A continuación explicaremos que tal anarquismo no una confesión de sus convicciones sino una reducción al absurdo de las nociones de ciencia propias del positivismo lógico y del racionalismo crítico. Feyerabend no postula positivamente el irracionalismo en la ciencia. Lo que demuestra es que la ciencia se presenta como una empresa irracionalista si esta es analizada desde los cánones del positivismo lógico o del racionalismo crítico. Reduce al absurdo los distintos intentos por establecer un criterio de demarcación que defina negativamente a la ciencia. Muestra cómo todos aquellos elementos que el positivista o el racionalista juzga como metafísicos o no científicos constituyen paradojalmente el seno del quehacer científico. Ahora bien, si no existe diferencia alguna entre lo que el positivismo lógico reconoce como metafísica y ciencia positiva, 
entonces la misma noción de ciencia formulada por aquellos es un concepto vacío. $\mathrm{O}$ en otras palabras, sus interlocutores deben reconocer que la ciencia es una empresa anárquica e irracional. Pero no porque la práctica científica sea en sí misma irracional sino porque tan positivismo como el racionalismo carece de explicación para los elementos metafísicos que inciden en la práctica científica. Después de todo, son ellos, y no Feyerabend, los que categorizan a estos elementos metafísicos como irracionales.

\section{Su ANARQUISMO EPISTEMOLÓGICO}

A lo largo de la década del 70 y del 80 Feyerabend se concentra en rebatir el racionalismo científico mostrando como sus ideales pueden conducir a un empobrecimiento de la misma ciencia. La finalidad de su famoso ensayo "Contra el Método" (1970) antecesor de sus tres versiones del Tratado contra el Método (1975, 1988 y 1993), no es otra sino criticar una racionalidad científica que pretende erigir el método como lo absoluto, como el fundamento y medida de la actividad científica.

A este racionalismo el filósofo opone una teoría anarquista que muestra cómo "[...] todas las metodologías, incluidas las más obvias tienen sus límites" (FEYERABEND, 1975/1992, p. 17). Siempre existen circunstancias que nos obligan no sólo a ignorar las escrupulosas y rígidas restricciones del método científico sino incluso a adoptar lo opuesto. Si el racionalista quiere un principio universal aplicable bajo cualquier circunstancia, el único criterio que tiene para ofrecerle - dirá Feyerabend con su ironía característica- es el principio «todo vale» (FEYERABEND, 1978/1982, p. 223). Por cierto, un principio vacío, inútil y bastante ridículo pero será un principio universal capaz de complacer el paladar de un racionalista (FEYERABEND, 1970/1989, p. 162-3).

Feyerabend no impugna las reglas metodológicas en cuanto tales. No obstante, niega el carácter de fundamento científico que le conceden -según el vienés- la gran mayoría de los epistemólogos de la ciencia. Las reglas y procedimientos metodológicos son resultado de atender a la misma dinámica o contexto particular de cada investigación científica. La ciencia es el resultado de investigar, no de seguir reglas epistemológicas abstractas e independientes de las circunstancias en las que cada investigación se realiza.

El filósofo está muy lejos de defender el irracionalismo del que habitualmente se lo acusa. El sugerente título de su obra Adiós a la razón 
(1987/2005) pretende expresar su rechazo no a la razón en cuanto tal sino a un modelo determinado de racionalidad, a la ingenua pretensión de fundamentar la racionalidad científica en una estrecha metodología, o más particularmente, a la concepción popperiana de racionalidad que no hace otra cosa que mutilar y diluir las vastas posibilidades del movimiento científico.

Pero no sólo se opone a la absolutización del método sino también a la absolutización de la ciencia occidental frente a todas las demás tradiciones de pensamiento. En La ciencia en una sociedad libre (1978/1982) denuncia las consecuencias sociales de un racionalismo que pretende erigirse como el principio configurador de todos los ámbitos de la vida humana y el intento occidental de imponer la ciencia como el paradigma de racionalidad.

Cuestiona la supuesta superioridad de la ciencia mostrando que aún no ha existido una instancia que justifique racionalmente a la misma. Si pretendemos fundar su superioridad en el método, Feyerabend (1978/1982, p. 114) muestra que no existe tal unidad o universalidad en el método. Si pretendemos justificar su superioridad en virtud de sus resultados, Feyerabend (1978/1982, p. 117) admite las prodigiosas contribuciones de la ciencia, pero alega que no sabemos si otras tradiciones podrían habernos ofrecido mejores resultados; resultados que se miden en función de la vida digna que ofrecen al ser humano.

Fueron motivos meramente políticos y propagandísticos, afirma Feyerabend (1978/1982, p. 123), los que causaron la hegemonía de la ciencia. Luego, la ciencia no es más que una tradición particular entre otras (Feyerabend, 1978/1982, p. 99). El Estado no puede privilegiar el racionalismo científico. De ahí, su propuesta de dejar que "[...] todas las tradiciones se desarrollen libremente" (FEYERABEND, 1978/1982, p. 124). La sociedad simplemente debe facilitar una estructura protectora a todas las tradiciones (FEYERABEND, 1978/1982, p. 149).

Ante la impotencia del positivismo y del racionalismo para ofrecer un fundamento que garantice la superioridad de la ciencia occidental sobre las demás tradiciones, nuestro filósofo (1977/1999, p. 204-205; 1978/1982, p. 12, 27, 99, 161) termina defendiendo positiva y explícitamente la razonabilidad del relativismo y se define a sí mismo como un relativista en el antiguo sentido de Protágoras.

El vienés refuta los falsos absolutos instituidos por la racionalidad científica y concomitantemente busca proponer una racionalidad más 
compleja, más rica, más humana que a la hora de validar una teoría no atiende únicamente a parámetros metodológicos o abstractos sino al contenido existencial implícito en su modelo político, económico, científico, ético o religioso. Estos argumentos lo conducen a escribir lo siguiente:

Tampoco deberíamos contentarnos con aumentar el contenido de verdad, el contenido empírico o cualquier otra cualidad. Comparadas con una vida plena y feliz estas cosas cuentan muy poco. Necesitamos una filosofía que dé a los hombres el poder y la motivación para hacer una ciencia más culta, en lugar de hacer una ciencia súper eficaz, súper verdadera, por un lado, pero tan bárbara, por otro, que degrada al hombre. Una filosofía así debe mostrar y probar todas las consecuencias de una existencia exigente, incluidas aquellas que no se pueden expresar por medio de palabras. Por eso no debe haber ninguna línea de demarcación entre filosofía y el resto de la vida humana. (FEYERABEND, 1978/1993, p. 27).

Robert Farrell muestra cómo el epistemólogo a una racionalidad entendida como un conjunto de reglas universales, necesarias y objetivas opone una racionalidad contextual, que responde a las idiosincrasias de la historia y a las situaciones particulares (FARRELL, 2003, p. 16).

Feyerabend asegura que no es una discusión abstracta y racional la que guía la vida de la sociedad sino que son sus mismos miembros inmersos en una situación histórica concreta quienes eligen, depuran y mejoran las tradiciones según el estilo de vida que quieren llevar (FEYERABEND, 1978/1982, p. 98100). El ciudadano debe ser libre de poder elegir el estilo de vida propuesto por cualquier tradición.

Pues bien, sólo esta racionalidad contextual será capaz de poner nuevamente a la ciencia y a todas las demás tradiciones al servicio del hombre. Solo ella podrá hacer del progreso científico algo positivo y eminentemente humano. La preocupación de Feyerabend por estos años puede sintetizarse en las siguientes líneas contenidas en "Consuelos para un especialista" (1970/1981, p. 359): “QQué valores elegiremos para poner a prueba las ciencias de hoy? A mí me parece que la felicidad y el completo desarrollo del ser humano individual sigue siendo el valor más alto posible"9.

De aquí que su concepción de la ciencia como una tradición más entre otras no solo supone abogar por una forma de relativismo sino que sobre todo

9 "[...] with what values shall we choose to probe the sciences of today? It seems to me that the happiness and the full development of an individual human being is now, as ever, the highest possible value". (T.N.). 
supone la búsqueda de una ciencia más humana. En este sentido su relativismo puede ser leído como la defensa de una ciencia más atenta y cercana a la vida del hombre y del ciudadano:

A finales de los años 80, Feyerabend amplia considerablemente el horizonte histórico e interdisciplinar ${ }^{10}$ pues no se pregunta ya únicamente por la ciencia occidental sino por cómo deben ser entendidas y abordadas todas y cada una de las tradiciones o culturas de las que ha sido parte la misma ciencia. No se limita a resolver si la ciencia es definida por lógica, por un método o por un contenido empírico, sino por cómo ésta ha sido valorada desde el origen y a lo largo de la historia del pensamiento humano. Se podría pensar que estos análisis de Feyerabend de la cultura suponen un abandono de las cuestiones específicas de la filosofía de la ciencia que lo comprometieron entre 1960 y 1980. No obstante, creemos que más que un abandono en estas nuevas consideraciones del vienés habría más bien, una reformulación de aquellos mismos problemas que trató en los 60 pero desde una perspectiva más amplia y comprehensiva. Por tanto, se puede decir que no hay propiamente un abandono o ruptura en su itinerario. Lo que hay es una ampliación temática y metodológica de horizontes en orden a acceder a una comprensión de la ciencia desde una perspectiva más comprehensiva.

A continuación, presentaremos como esta ampliación temática le permitió formular una metafísica de la abundancia en virtud de la cual supera su antigua posición relativista y formula lo que podría ser entendido como un nuevo fundamento para la racionalidad científica.

\section{UNA RACIONALIDAD NO-RELATIVISTA NI ABSOLUTISTA (1980-1990)}

A fines de la década de los 80 y principios de los 90 Feyerabend busca alejarse del relativismo político que sostuvo en los 70 como consecuencia indirecta de su lucha contra el racionalismo. En Diálogos del conocimiento (1991a) afirma que no podemos simplemente dejar en paz las tradiciones pues éstas por su propia naturaleza se expanden más allá de sus fronteras y abruman a las oponentes más débiles (FEYERABEND, 1991a, p. 104-5). De aquí la necesidad de detenerse a considerar el valor intrínseco de las tradiciones y de las formas de vida que ellas proponen.

${ }^{10}$ Tanto la historia, la arqueología, la antropología social, la psicología, la historia del arte clásico prestan su auxilio a los estudios del vienés sobre las distintas culturas. 
El vienés (1991a, p. 111-114, 121-123) explica que tanto en su Tratado contra el método como en La Ciencia en una Sociedad Libre sostuvo que la ciencia era una tradición de conocimiento entre otras. Esta tesis implicaba dos cosas: primero, que la realidad permite enfoques distintos, entre ellos el científico; y segundo, que el conocimiento (la verdad) es una noción relativa. Pero confiesa haberse retractado, puntualmente en 1987, de esta primer forma de relativismo para formular nueva forma de relativismo que reconoce como un relativismo cosmológico. Desde Adiós a la Razón (1987/2005) el vienés cuenta haber abogado por un relativismo cosmológico como parte de una ciencia no dogmática que se caracteriza por la defensa de la primera tesis y por el rechazo de la segunda. (cf. FEYERABEND 1991b, p. 519; 1993/2008, p. 270-271). A saber, la realidad permite ser vista y analizada desde distintas aristas socio-históricas pero ella no es en si misma una noción relativa.

Estos giros en la obra de Feyerabend no parecen ser tenidos en cuenta por Harris (1992) quien trayendo a colación citas sacadas de su contexto presenta su pensamiento en el marco de un relativismo radical. Preston (1997b, p. 424 y 427; 2000, p. 94-96), por otro lado, obviando las confesiones y las distintas argumentaciones por las cuales el vienés busca superar su antiguo relativismo, asegura que en sus últimas obras Feyerabend evolucionó hacia un relativismo tan extremo como el cosntructivismo social.

Dichos críticos no parecen atender a los extensos pasajes donde Feyerabend lucha por no repetir la falacia del relativismo. En La Conquista de la Abundancia (1994/2000) afirma que muchas tradiciones han sido aprobadas por el Ser, en la medida que proponen a sus miembros una vida buena y plena. Otras tradiciones, en cambio, no reciben jamás esta aprobación por parte del Ser:

De este modo la mera existencia de una sociedad con determinadas formas de comportamiento y ciertos criterios de valoración de lo que se ha logrado, no es suficiente para poder establecer una realidad manifiesta. También se necesita que Dios, o el Ser, o la realidad fundamental, reaccionen de manera positiva. (FEYERABEND, 1994/2000, p. 253-254).

Según el vienés, esta resistencia o aprobación del Ser es justamente lo que no tienen en cuenta los constructivistas o relativistas (FEYERABEND, 1994/2000, p. 173). Para él: "No todas las proyecciones son exitosas" (FEYERABEND, 1994/2000, p. 168) pues la naturaleza o el Ser «[...] no es algo amorfo a lo que se le pueda dar cualquier forma. Resiste y mediante su resistencia revela sus propiedades y leyes» (FEYERABEND, 1994/2000, 
p. 280). No todas tienen su aprobación por parte del Ser y por tanto carecen de contenido ontológico. En cambio, para un relativista o constructivista toda proyección es válida. Las entidades no son más que un producto de un contexto histórico determinado. En orden a evitar que su obra tardía sea inscripta en los límites de un constructivismo social, escribe:

[...] otros importan el término "relativismo" y me lo aplican. Pero todavía les puedo corregir de la siguiente manera.

Para empezar, no todas las formas de abordar la "realidad" tienen éxito. Como ocurre con las mutaciones inadaptadas, algunos enfoques sobreviven durante un tiempo -sus agentes sufren, muchos mueren- $y$, entonces, desaparecen. Así, la mera existencia de una sociedad con ciertos modos de conducta y ciertos criterios para juzgar lo que se ha conseguido no es suficiente para establecer una realidad manifiesta, también hace falta que Dios, el Ser, o la Realidad Básica, reaccione de un modo positivo. Sea lo que sea, el relativismo que aparece en este artículo no es, por lo tanto, una posición filosófica, sino un hecho empírico que recibe el apoyo de una multiplicidad de enfoques y resultados procedentes de muchos campos distintos. (FEYERABEND, 1994/2000, p. 253-254).

El conocimiento, para nuestro epistemólogo, es simplemente el equilibrio entre un Ser complejo y abundante y los hombres que lo interrogan desde una tradición determinada. No son las conclusiones racionales, por más lógicas que éstas sean, el criterio para acepar una teoría científica o cosmovisión. Es la existencia humana y la tradición en la que ella está inscripta lo que define lo real. Esta misma idea es expresada por el vienés en forma dialogo:

Lee Feng: ¿Quieres decir que el hombre y toda una cultura son medida, pero que Ser es también una medida y que sea cual fuere el mundo en que vivimos, siempre será resultado de la interacción de estas dos medidas?

Charles: Sí; lo has expresado perfectamente. (FEYERABEND, 1991a, p. 66).

Lo verdadero es el equilibrio que existe entre el Ser y nuestra cultura. O quizás mejor, siendo ese equilibrio su condición, lo verdadero sería el Ser en cuanto manifestado o realizado en la cultura. Instaurar una escisión entre el Ser y la cultura, entre el mundo y la cultura sería para él repetir nuevamente las dialécticas de la modernidad entre hechos y teorías, entre objeto y sujeto, entre objeto real y objeto teórico, entre método y teoría... 
Feyerabend pretende situar este equilibrio entre el Ser y la cultura como el fundamento último del conocimiento. $\mathrm{O}$, en otras palabras, entiende que la empresa de la modernidad de fundamentar el conocimiento fracasa cuando se busca concretarla instaurando las dialécticas recién mencionadas.

Farrell (2003, p. 122 y ss.) ha caracterizado justamente la visión metafísica y epistemológica tardía del vienés por el abandono de todas las dicotomías de racionalismo/idealismo, relativismo/absolutismo, sujeto/ objeto. Para nuestro filósofo plantear la dialéctica entre ellas no es más que una cuestión imaginaria que carece de sentido y que no prestan ningún servicio para entender la ciencia y la cultura. Ya en su Ciencia en una Sociedad Libre, consideraba a "los enfoques sujeto-objeto del conocimiento como intentos especialmente problemáticos de comprender nuestro papel en el mundo" y en su lugar recomendaba "una crítica cosmológica de las metodologías" (FEYERABEND 1978/1982, p. 183, n. 9). Ahora bien, a través de esta crítica cosmológica Feyerabend parecería haber entendido la necesidad de subrayar el equilibrio y la síntesis que existe entre el Ser y la cultura, entre los hechos y la teoría, entre lo objetivo y lo subjetivo. Las culturas, el conocimiento y la ciencia no pueden explicadas mediante antítesis o dialécticas de este tipo. Por el contrario, estas solo pueden ser explicadas si se entiende la síntesis indisoluble que existe entre ellas.

En el punto dos vimos los argumentos por los cuales Feyerabend sostiene que la racionalidad científica no puede ser justificada ni fundamentada por núcleo empírico, por un conjunto de normas metodológicas universales así como tampoco por un conjunto de valores tales como la adecuación empírica o la simplicidad, como pretende Kuhn. Pues toda revolución científica -tal como intenta mostrar con su doctrina de la inconmensurabilidad - supone un cambio radical de un conjunto determinado de valores. El sistema de valores que anima a una teoría o paradigma es correlativo a estas revoluciones. De aquí que en la ciencia convive una pluralidad de paradigmas o teorías por lo cual coexisten en ella diversas concepciones inter-teóricas de racionalidad. Ahora bien, esto exige una nueva concepción de la racionalidad científica cuya formulación ya era un propósito explícito para él desde el año 1977. En ese entonces publica un artículo titulado Solicitud de un Año Sabático donde explica que la tarea que le queda por delante es la de formular un nuevo modelo de ciencia o racionalidad:

Resultado: ni el contenido, ni el método, ni las reglas de la razón nos autorizan a separar la ciencia de la no-ciencia. Toda separación producida 
es un fenómeno local; se produce bajo ciertas condiciones, entre ciertas partes de la ciencia y ciertas partes de la no-ciencia, y no pueden utilizarse para inferir una diferencia esencial entre las cosas separadas.

Plan a largo plazo

Mi plan a largo plazo es construir una teoría del conocimiento que tenga en cuenta esta situación. Esta teoría diferirá en dos aspectos de las teorías del conocimiento al uso:

1. Será una teoría de las ciencias tanto como de las artes (humanidades). En lugar de ver las ciencias y las artes como dos dominios diferentes, presentará a ambos como partes diferentes de una y la misma empresa, del mismo modo que la física y la biología aún son vistas como partes de una y la misma empresa: la ciencia.

2. No contendrá reglas abstractas. Todas las reglas, las de la lógica incluida, quedaran vinculadas a un contexto bien especificado, y dará una razón histórica del contexto y del correspondiente uso de reglas. (FEYERABEND, 1977/2013, p. 302-303).

Veinte ańos después, en Ambigüedad y Armonía Feyerabend escribe: "[...] no puede haber descubrimientos a menos que se abandone la casa razón o que la casa de la razón sea muy diferente de cómo la han pintado los filósofos y otros traficantes de ideas" (FEYERABEND, 1999, p. 152) - escribe. Pues bien, el vienés busca caracterizar esta casa de la razón de modo que no repita nuevamente los errores tanto del relativismo como del racionalismo:

[...] el relativismo es tan quimérico como su irritable hermano gemelo, el absolutismo o el objetivismo. [...] Los objetivistas universalizan las leyes vigentes dentro de las fronteras del tema preferido, mientras que los relativistas insisten en la validez limitada de las leyes, dentro de las mismas fronteras. (FEYERABEND 1991a), p. 114-115) ${ }^{11}$.

No es lícito - sostiene Feyerabend (1991/2003, p. 87) - atribuir a las teorías o principios científicos un carácter universal transhistórico y necesario tal como, según él, hace tanto el relativismo como el objetivismo. Contra ambos argumenta que los entes conocidos, las características descubiertas en un sector del mundo son siempre relativos a una cultura o teoría circunscripta a un escenario histórico determinado. El contenido cognoscitivo que develamos

\footnotetext{
${ }^{11}$ Para un estudio crítico acerca de la comprensión que alcanza Feyerabend de la dicotomía objetivismo/ relativismo se puede ver Jary (1991) y Farrell (2003, p. 101 y ss).
} 
en el Ser depende de las herramientas técnicas, de los conocimientos, del lenguaje, de las tradiciones culturales, sociales, religiosas, etc. con que abordemos su estudio. Atribuir un carácter universal a los resultados aportados por los instrumentos disponibles en ese momento o, afirmar que estos son válidos independientemente del enfoque utilizado no es más que el resultado de haber objetivado la ontología de una teoría específica.

Feyerabend en sus últimas obras se opone a considerar la racionalidad como un conjunto de reglas universales, necesarias y objetivas. En su lugar propone una racionalidad inherentemente histórica y flexible, una racionalidad contextual que responde a las idiosincrasias de la historia y a las situaciones particulares. Para el vienés el lenguaje, las manifestaciones artísticas, las costumbres e incluso los principios que expresan una visión del mundo cambian en función de las situaciones históricas en que son usados. La ambigüedad del lenguaje, el arte, el comercio, las decisiones políticas pueden constituir posibles vías que facilitan el carácter abierto, la comunicación, la mutua interdependencia, y la transición de una visión del mundo a otra (cf. FEYERABEND, 1991/2003, p. 63). De aquí que le se presente como absurdo postular un relativismo o un racionalismo que construye límites o barreras culturales que no existen en la práctica (cf. FEYERABEND, 1991/2003, p. 108-109). Feyerabend (1991/2003, p. 109) no niega las diferencias que existen entre las culturas o cosmovisiones. Pero atribuye tales diferencias a accidentes históricos y no a esencias culturales claras, inequívocas e inmóviles.

No podemos presentar los resultados obtenidos en un experimento como la imagen verdadera, y objetiva de la naturaleza o el mundo. Quizás estos resultados sean verdaderos y reales - en el caso de que el Ser los confirmepero siempre su veracidad o realidad será relativa al conjunto de circunstancias en las cuales el experimento fue conducido. Bajo otras circunstancias y condiciones podemos encontrar otros resultados, es decir, otras leyes o fenómenos igualmente válidos.

[...] la naturaleza tal y como la describen los cientificos no es la naturaleza en y para si misma, sino que es el resultado de una interacción o intercambio, entre dos partes bastantes desiguales: diminutos hombres y mujeres, por una parte, y el Ser majestuoso, por otra. (Feyerabend, 1994/2000, p. 281, las cursivas son del original).

Feyerabend, en sus últimos años, arriba a una noción analógica de Ser o mundo que se le presenta como ineludible para superar su antiguo relativismo. 
Tal noción le permitió superar el historicismo de Kuhn, sin dejar por ello de subrayar el aspecto contextual de la ciencia y del conocimiento. Es difícil caracterizar positivamente, o decir qué es, esta entidad. Lo fue para él; y por eso utiliza, diversos términos -Dios, Ser, mundo, realidad. La tarea crítica que ha llevado a Feyerabend hasta ese Ser determina mucho más claramente lo que no es que lo que es positivamente. Empero, se puede decir con seguridad que sería traicionar profundamente el íntimo movimiento de su pensamiento si no se afirmara que el abandono de su anterior relativismo y su reformulación de un relativismo cosmológico es dependiente de esta noción de Ser postulada en su metafísica de la abundancia.

Pero su metafísica de la abundancia no solo puede ser interpretada como un intento de superar su relativismo. También, y sobre todo, debe ser entendida como una crítica al racionalismo. El subtítulo de la obra póstuma de Feyerabend: La abstracción frente a la riqueza del ser (1994/2000) refleja se intención de elaborar una metafísica capaz de fundar una concepción de las culturas y, por ende también de la ciencia, que trascienda los estrechos estándares del racionalismo. A las vacías y pobres abstracciones de los racionalistas contrapone la complejidad y riqueza de un Ser que se manifiesta en la abundancia de lo real. Subraya la riqueza de un mundo irreductible a los constructos teóricos. Postula la existencia de un Ser inasible al entendimiento humano en orden a mostrar que "[...] el mundo es mucho más escurridizo de lo que admiten nuestros racionalistas” (FEYERABEND, 1994/2000, p. 283).

Para Feyerabend el conocimiento es una empresa que busca el descubrimiento de nuevos objetos y relaciones en el mundo. Destaca además que para alcanzar tal conocimiento son necesarias las simplificaciones que se consiguen a través de la abstracción. Ésta permite eliminar ciertos rasgos peculiares que distinguen a un objeto de otro. Feyerabend no objeta a las abstracciones en sí, sino a la actitud de los racionalistas por la cual se concibe como 'real' el resultado de dicha abstracción es decir, "que se considera como algo más importante que la propia realidad" (FEYERABEND, 1994/2000, p. 25). Cuestiona la impotencia de los racionalistas para considerar la abundancia como un valor en sí mismo:

Los individuos y grupos a los que me refiero rechazaron considerar la abundancia como un valor en sí mismo evidente. Negaron que el mundo fuera tan rico, el conocimiento tan completo, y el comportamiento tan libre como el sentido común, las artes y las creencias religiosas de su tiempo presuponían. Al tratar de articular su negación introdujeron toscas dicotomías del tipo real/aparente, conocimiento/opinión, correcto/ 
pecaminoso. Los primitivos filósofos y científicos griegos, en particular, presuponían que el "mundo real" que ellos revelaban de esta manera era simple, uniforme, estaba sometido a principios estables, y era el mismo para todos. (FEYERABEND 1994/2000, p. 33-34).

Feyerabend postula una entidad a la que designa con el nombre de Dios, mundo, materia o Ser con mayúscula que no puede ser reducido a principios uniformes, ni explicado mediante leyes estables. En contraposición con las sistematizaciones propias del racionalismo la describe como una entidad inagotable (cf. FEYERABEND, 1987/2005, p. 78; 1994/2000, p. 37), compleja (cf. FEYERABEND, 1975/1992, p. 4; 1987/2005, p. 70; 1994/2000, p. 33, 169), infinita y "[...] de una abundancia que sobrepasa nuestra imaginación más desatada” (cf. FEYERABEND, 1994/2000, p. 23).

Finalmente, a través de esta metafísica de la abundancia junto con su concepción de las culturas y su concomitante abandono de su relativismo y del problema de la inconmensurabilidad Feyerabend arriba a una nueva comprensión de la ciencia como un continuo devenir de cosmovisiones mitológicas y filosóficas. Los límites entre la ciencia, el mito y la filosofía quedan desdibujados ante la nueva noción de cultura que propone como resultado del abandono del problema de la inconmensurabilidad. Feyerabend deja de considerar la inconmensurabilidad como un problema en la medida que comprende que ésta solo sólo constituye una objeción contra determinados modos de concebir la ciencia: significa un obstáculo para el positivismo lógico que insiste en la rigidez del significado de los términos y que intenta explicar el progreso científico mediante la reducción lógica de las antiguas teorías a las nuevas. También supone una crisis para el racionalista crítico que concibe como reales solo aquellas entidades que son fruto de las abstracciones o experimentaciones efectuadas desde sus propios esquemas conceptuales (FEYERABEND, 1970/1989, p. 108). Pero atendiendo a la ambigüedad del lenguaje, a la interacción existente entre las culturas Feyerabend infiere que la inconmensurabilidad no es una característica que describa las relaciones reciprocas que se establecen entre las culturas. Por eso explica:

Déjenme repetir que las culturas invocan una cierta realidad y que estas realidades por si mismas no están nunca bien definidas. Las culturas cambian, interactúan con otras culturas y el resultado indefinido es reflejado en sus mundos. Esto es lo que hace la comprensión intercultural y el cambio científico posible: cada cultura es potencialmente todas las culturas. (FEYERABEND, 1993/2008, p. 271-272). 
Luego la ciencia - entendida como parte de la cultura occidental - evoluciona y fluctúa a lo largo de la historia interactuando con diversos mitos y cosmovisiones del mundo. Por ejemplo, la noción de átomo, según Feyerabend, tiene su origen en la noción milenaria de átomo propia del atomismo de los antiguos griegos pero en la medida que este concepto filosófico es susceptible de ser modificado por otras culturas sobrevive hasta nuestros días aunque con pocas semejanzas con la noción original. La adaptación y la evolución del concepto de átomo a lo largo de la historia posibilitan que aquella entidad indivisible devenga en las partículas divisibles de Dalton y luego en los comportamientos cuánticos de la mecánica cuántica (FEYERABEND, 1991/2003, p. 81; 1996, p. 27-28).

Por otro lado, la coexistencia de múltiples visiones del mundo con sus respectivos presupuestos metafísicos en la ciencia es otro de los argumentos por los cuales Feyerabend aboga por su comprensión de la ciencia como fruto de múltiples tradiciones filosóficas (FEYERABEND, 1991/2003, p. 179-180; 1993/2008, p. 242-245; 1994/2000, p. 171-172, 178, 184; I 994/200o, p. I64I65) o como "[...] una colección de materias heterogéneas" (FEYERABEND, 1994/2000, p. 230) que provienen de campos disciplinares aislados.

La ciencia, el mito y la filosofía no constituyen culturas cerradas sino que, por el contrario, se suceden en una continua y recíproca interacción conformando un único proceso histórico a partir del cual se configura la ciencia occidental. De aquí que no exista una definición de ciencia que cubra todas las formas posibles de su evolución:

Pero, tal como intente demostrar en el Contra el método y también en Ciencia en una sociedad libre (Siglo XXI, 1982) no existe ninguna definición de ciencia que cubra todas las formas posibles de evolución y no existe ningún modo de vida que no sea capaz de absorber radicalmente nuevas situaciones. Los conceptos, especialmente los conceptos "básicos" de las visiones del mundo nunca están totalmente asentados; están mal definidos, son ambiguos, fluctúan entre interpretaciones "inconmensurables", y deben hacerlo para posibilitar el cambio (conceptual). Así que, en cierto modo, los errores del relativismo filosófico y del objetivismo se remontan a la idea de Platón, según la cual los conceptos son estables y de una claridad inherente, y el conocimiento nos conduce de la ilusión al descubrimiento de esta claridad. (FEYERABEND, 1991/2003, p. 115).

Contra los filósofos de la ciencia que buscan definir la actividad científica, mediante cánones abstractos, Feyerabend (1991a, p. 115) la 
presenta como una tradición que se manifiesta históricamente heterogénea. La ciencia es, en sí misma, una tradición histórica. Y ante la pregunta por la estructura propia de esta tradición y por los elementos que la distinguen de las demás tradiciones, Feyerabend responde que la ciencia posee una estructura que se define en función de las múltiples tradiciones mitológicas y filosóficas que la atraviesan históricamente:

Las generalizaciones intelectuales en torno al "arte", "la naturaleza" o "la ciencia” son recursos simplificadores que pueden ayudarnos a ordenar la abundancia que nos rodea. Así es como deben ser entendidas, como herramientas oportunistas, no como enunciados finales sobre la realidad objetiva del mundo. (FEYERABEND, 1991/2003, p. 133).

Ni la teología, ni la filosofía, ni el mito, ni el arte se le presentan a Feyerabend (1991/2003, p.80; 1994/2000, p. 198-199, 228-229) como formas alternativas e inconmensurables a la ciencia; pues la misma ciencia es en sus orígenes y en su desarrollo histórico teológica, mitológica y artística.

\section{Conclusión}

A modo de conclusión podríamos inferir que una de las claves que nos permite comprender la unidad o continuidad lógica del pensamiento de Feyerabend es su constante esfuerzo por superar los pseudos fundamentos del conocimiento científico instituidos por el positivismo lógico y el racionalismo científico. En los 60, contra el positivismo lógico que erige la experiencia como el juez supremo de las teorías científicas, Feyerabend advierte la presencia de elementos metafísicos en las mismas proposiciones y observaciones empíricas. Entre los años 70 y 80, muestra las repercusiones sociales de un racionalismo científico que presenta el método como fundamento de la actividad científica y medida de racionalidad. Ya, al final de su vida, desarrolla una metafísica capaz de ofrecer una nueva teoría del conocimiento o racionalidad científica que trascienda las coordenadas tanto del relativismo como del racionalismo. En líneas generales se podría sostener que uno de los grandes méritos de este filósofo del siglo XX estriba en haber denunciado el fracaso de los intentos de definir dialécticamente la ciencia a través de una delimitación con lo metafísico. $\mathrm{O}$, dicho de un modo positivo, en haber propuesto pensar la ciencia en continuidad con el mito y la filosofía y haber demostrado, concomitantemente, que una ciencia humana es posible por su corazón metafísico. 
GARGIULO, Teresa. Paul Karl Feyerabend: a defense of the continuity of his thought. Trans/Form/Ação, Marília, v. 38, n. 2, p. 129-162, Maio/Ago., 2015.

\begin{abstract}
A common element in studies of Paul Karl Feyerabend is the distinction between five periods in his work. John Preston sees a radical discontinuity between the early and late versions of Feyerabend's thought. All of this contributes our having a fragmented and incomplete view of a thinker who continued to evolve until 1994, the year of his death. We aim to provide an explanation of his intellectual journey that shows the evident continuity and unity of his thought. We will discuss the various issues he addressed in the different periods of his life, but at the same time we will emphasize the unity or logical coherence among them. Our aim is to understand the reasons why the philosopher of science changed his distinct foci of discussion and criticism.
\end{abstract}

KEYWORDS: Feyerabend. incommensurability. absolute. logical positivism. rationalism.

\title{
Bibliografía
}

ACHINSTEIN, P. On the meaning of scientific terms. Journal of Philosophy, v. 61, p. 497-509, 1964.

BOYD, R. Constructivism, realism and philosophical method, inference explanation, and other frustrations. In: EARMAN, J. (Ed.). Essays in the philosophy of science. Berkeley: University of California Press, 1992. p. 131-198.

BRONNCANO, F. Introducción. uno de los nuestros. In: . Ambigüedad y armonía. Barcelona: Paidós, 1999. p. 7-32,

COUVALIS, G. Review Symposia: radical fallibilism vs conceptual analysis: the significance of Feyerabend's Philosophy of Science. Metascience, v. 8, p. 206-216, 1999.

CULP, S. Objectivity in experimental inquiry: breaking data-technique circles. Philosophy of Science, v. 62, p. 430-450, 1995.

FARRELL, R. Will the Popperian Feyerabend please step forward: pluralistic, Popperian themes in the philosophy of Paul Feyerabend. International Studies in the Philosophy of Science, v. 14, p. 257-266, 2000.

Feyerabend and scientific values. tightrope-walking rationality. Netherlands: Kluwer Academic Publishers, 2003.

FEYERABEND, P. K. Review of Wittgenstein's Philosophical Investigations. The Philosophical Review, v. 64, p. 449-483, 1955.

. A Note on the paradox of analysis. Philosophical Studies, v. 7, p. 92-96, 1956.

. Review of foundations of quantum- mechanics: a study in continuity and symmetry. By A. Landé. British Journal for the Philosophy of Science, v. 7, p. 354-357, 1957. . Complementarity. Proceedings of Aristotelian Society, Suppl., v. 32, p. 75-104, 1958. 
An attempt at a realistic interpretation of experience. In: Realism, rationalism and scientific method, Philosophical Papers Volume 1. Cambridge: Cambridge University Press, 1958/1981a. p. 17-36.

Reichenbach's Interpretation of Quantum Mechanics. In: . Realism, rationalism and scientific method. Cambridge: Cambridge University Press, 1958/1981b. p. 236-246. (Philosophical Papers, v. 1).

. Review of patterns of discovery. an inquiry into the conceptual foundations of science. By N. R. Hanson. The Philosophical Review, v. 69, p. 247-252, 1960.

. On the interpretation of scientific theories. In: Realism, rationalism and scientific method. Cambridge: Cambridge University Press, 1960/1981a. p. 37-43. (Philosophical Papers, v. 1).

. Professor Bhom's Philosophy of Nature. In: Realism, rationalism and scientific method. Cambridge: Cambridge University Press, 1960/1981b. p. 219-235. (Philosophical Papers, v. 1).

. The Problem of the existence of theoretical entities. In: PRESTON, J. (Ed.). Paul $K$. Feyerabend: knowledge, science and relativism. Cambridge: Cambridge University Press, 1960/1999. p. 16-49. (Philosophical Papers, v. 3).

. Two Letters of Paul Feyerabend to Thomas S. Kuhn on a Draft of The Stucture of Scientific Revolutions. By Paul Hoyningen-Huene. Studies in History and Philosophy of Science, part A, v. 26, p. 353-387, 1961/1995.

. Knowledge without foundations. In: PRESTON, J. (Ed.). Paul K. Feyerabend: knowledge, science and relativism. Cambridge: Cambridge University Press, 1961/1999. p. 50-70. (Philosophical Papers, v. 3).

. Hidden variables and the argument of Einstein, Podolsky and Rosen. In:

Realism, rationalism and scientific method. Cambridge: Cambridge University Press, 1962/1981a. p. 298-342. (Philosophical Papers, v. 1).

Explanation, Reduction and Empiricism. In: Realism, rationalism and scientific method. Cambridge: Cambridge University Press, 1962/1981b. p. 44-96. (Philosophical Papers, v. 1).

Limites de la ciencia: explicación, reducción y empirismo. Barcelona: Paidós, 1962/1989.

. Review of Erkenntnislehre. By Victor Kraft. The British Journal for the Philosophy of Science, v. 13, p. 319-323, 1963.

- Materialism and the mind-body problem. In: Realism, rationalism and scientific method. Cambridge: Cambridge University Press, 1963/1981. p. 161-175. (Philosophical Papers, v. 1).

. Review of Scientific Change. By A. C. Crombie. The British Journal for the Philosophy of Science, v. 15, n. 59, p. 244-254, 1964. 
. Problems of Empiricism. In: COLODNY, R. (Ed.). Beyond the edge of certainty. essays in contemporary science and philosophy. Pittsburg: CPS Publications in the Philosophy of Science, 1965. p. 145-260.

. On the "Meaning" of scientific terms. In: Realism, rationalism and scientific method. Cambridge: Cambridge University Press, 1965/1981a. p. 97-103. (Philosophical Papers, v. 1).

. Reply to Criticism. Comments on Smart, Sellars and Putnam. In: Realism, rationalism and scientific method. Cambridge, Cambridge University Press: 1965/1981b, p. 104-131. (Philosophical Papers, v. 1).

$1966 \mathrm{a}$

. Dialectical materialism and the quantum theory. Slavic Review, v. 25, p. 414-417,

Herbert Feigl: A biographical Sketch. In: FEYERABEND, P.; MAXWELL, G. (Ed.). Mind, matter and method: essays in philosophy and science in honor of Herbert Feigl. Minneapolis: University of Minnesota Press, 1966b. p. 3-13.

. On a Recent critique of complementarity: part I. Philosophy of Science, v. 35, p. 309-331, 1968.

. Consolations for the Specialist. In: Problems of Empiricism. Cambridge: Cambridge University Press, 1970/1981. p. 131-167. (Philosophical Papers, v. 2).

. Contra el método: esquema de una teoría anarquista del conocimiento. Barcelona: Ariel, 1970/1989.

- Tratado contra el método: esquema de una teoría anarquista del conocimiento. Madrid: Tecnos, 1975/1992.

. Let's Make More Movies. In: PRESTON, J. (Ed.). Paul K. Feyerabend: Knowledge, Science and Relativism, Philosophical Papers Volume 3. Cambridge: Cambridge University Press, 1975/1999. p. 192-199.

. Rationalism, Relativism and Scientific Method. In: PRESTON, J. (Ed.). Paul K. Feyerabend: knowledge, science and relativism. Cambridge: Cambridge University Press, 1975/1999. p. 200-211. (Philosophical Papers, v. 3).

. Solicitud de un Año Sabático. In: Filosofía Natural. Buenos Aires: Debate, 1977/2013. p. 295-310.

- La ciencia en una sociedad libre. Trad. Alberto Elena. Madrid: Veintiuno, $1978 / 1982$.

- ¿Por qué no Platón? Madrid: Tecnos, 1978/1993.

. Introduction: scientific realism and philosophical realism. In: Realism, rationalism and scientific method. Cambridge: Cambridge University Press, 1981. p. 3-16. (Philosophical Papers, v. 1).

Adiós a la Razón. 3. ed. Madrid: Técnos, 1987/2005. 
. Tratado contra el método. 2. ed. Madrid: Tecnos, 1988.

- Diálogos sobre el conocimiento. Madrid: Cátedra, 1991a.

. Concluding unphilosophical conversation. In: MUNÉVAR, G. (Ed.). Beyond reason: essays on the Philosophy of Paul Feyerabend. Dordrecht: Kluwer, 1991b. p. 487527. (Boston Studies in the Philosophy of Science, v. 132)

. Provocaciones Filosóficas. Madrid: Biblioteca Nueva, 1991/2003.

. Against Method. 3. ed. London: Verso, 1993/2008.

. Matando el Tiempo. Madrid: Debate, 1994/1995.

. La Conquista de la abundancia: la abstracción frente a la riqueza del ser. Comp. Bert Terpstra. Barcelona: Paidós, 1994/2000.

. Theoreticians, artists and artisans. Leonardo: Journal of the International Society for the Arts, Sciences and Technology, v. 29, p. 23-28, 1996.

GELLNER, E. Review of beyond truth and falsehood. The British Journal of Philosophy of Science, v. 26, p. 331-342, 1975.

GENTILE, N. El camino de Feyerabend: crítica, proliferación y realismo. Filosofía Unisinos, v. 8 p. 109-127, 2007.

HACKING, I. Why does language matter to philosophy? Cambridge: Cambridge University Press, 1975.

HAHN, H.; NEURATH, O.; CARNAP, R. La concepción científica del mundo: el Círculo de Viena. REDES, v. 18, p. 103-149, 2002.

HARRIS, J. Against relativism: a philosophical defense of method. La Salle: Open Court, 1992.

HEMPEL, C.; OPPENHEIM, P. Studies in the logic of explanation. Philosophy of Science, v. 15 , p. $135-175,1948$.

HENTSCHEL, K. On Feyerabend's version of Mach's theory of research and its relations to Einstein. Studies in History and Philosophy of Science, part A, v. 16, p. 387-394, 1985.

HOOKER, C. Between Formalism and anarchism: a reasonable middle way. In: MUNÉRVAR, G. (Ed.). Beyond reason: essays on the philosophy of Paul Feyerabend. Dordrecht: Kluwer Academic Publishers, 1991. p. 41-107.

HUME, D. Investigación sobre el entendimiento humano. Madrid: Istmo, 2004.

JARY, D. Beyond Objectivity and relativism: Feyerabend's "Two argumentative chains" and sociology. In: BUCZKOWSKI, P. (Ed.). The Social horizon of knowledge. Amsterdam: Rodopi, 1991. p. 39-57. (Poznan Studies in the Philosophy of Sciences and the Humanities, v. 22) 
KADVANY, J. Reason in history: Paul Feyerabend's autobiography. Inquiry, v. 39, p. 141$146,1996$.

KANT, I. Crítica de la razón pura. Buenos Aires: Losada, 2003.

KITCHER, P. The Naturalist return. The Philosophical Quarterly, v. 101, p. 53-115, 1992.

KLIMOVSKY, G. Las desventuras del conocimiento cientifico: una introducción a la epistemología. 5. ed. Buenos Aires: A-Z, 2001.

MAIA NETO, J. R. Feyerabend's skepticism. Studies in History and Philosophy of Science, part A, v. 22, n. 4, p. 543-555, 1991.

MUNÉVAR, G. Reviews Symposia: radical fallibilism vs conceptual analysis: the significance of Feyerabend's philosophy of science. Metascience, v. 8, p. 216-226, 1999.

MUSGRAVE, A. Evidential support, falsification, heuristics, and anarchism. In: RADNITZKY, G.; ANDERSSON, G. (Eds.). Progress and rationality in science. Dordrecht: D. Reidel, 1978. p. 181-201.

NAGEL, E. La estructura de la ciencia. Barcelona: Paidos, 1961/1981.

OBERHEIM, E. Feyerabend's Philosophy. Berlin: Walter de Gruyter, 2006. (Quellen Und Studien Zur Philosophie, v. 73).

; HEIT, H. Paul Feyerabend como filósofo de la naturaleza: introducción. In: FEYERABEND, P. Filosofia Natural. Buenos Aires: Debate, 2013. p. 9-35.

; HOYNINGUEN-HUENE, P. Incommensurability, realism and metaincommensurability. Theoria, v. 12, p. 447-465, 1997.

. Reviews Symposia: radical fallibilism vs conceptual analysis: the significance of Feyerabend's philosophy of science. Metascience, v. 8, p. 226-233, 1999.

PRESTON, J. Feyerabend: philosophy, science and society. Oxford: Blackwell, 1997a.

. Feyerabend's retreat from realism. Philosophy of Science, v. 64, p. 421-431, 1997b.

- Reviews Symposia: radical fallibilism vs conceptual analysis: the significance of Feyerabend's philosophy of science. Metascience, v. 8, p. 233-243, 1999.

. Science as supermarket: "post-modern" themes in Paul Feyerabend's later philosophy of science. In: PRESTON, J.; MUNÉVAR, G.; LAMB, D. (Eds.). The Worst enemy of science? Essays in memory of Paul Feyerabend. New York: Oxford University Press, 2000. p. 80-IOI.

PUTNAM, H. How not to talk about meaning. In: COHEN, R.; WARTOFSKY, M. (Eds.). In Honor of Philipp Frank. New York: Humanities, 1965. (Boston Studies in the Philosophy of Science, v. 2)

RORTY, R. Philosophy and the mirror of nature. Oxford: Basil Blackwell, 1980. 
SHAPERE, D. Meaning and the scientific change. In: COLODNY, R. (Ed.). Mind and cosmos. Pittsburgh: Pittsurgh University Press, 1966. p. 41-85.

SHAPIN, S. Phrenological knowledge and the social structure of early Nineteenth Century Edinburgh. Annals of Science, v. 32, p. 219-243, 1975.

WATKINS, J. Feyerabend among Popperians 1948-1978. In: PRESTON, J.; MUNÉVAR, G.; LAMB, D. (ed.). The Worst enemy of science? Essays in memory of Paul Feyerabend. New York: Oxford University Press, 2000. p. 47- 57.

ZAHAR, E. Second thoughts about Machian positivism: a replay to Feyerabend, The British Journal for the Philosophy of Science, v. 32, p. 267-276, 1981.

Recebido / Received: 01/10/2014

Aprovado / Approved: 10/11/2014 